عوامل مرتبط با فعاليت جسمانى بر اساس "الكوى بزنف" در دانشجويان يرديس دانشعاه علوم يزشكى كرمان

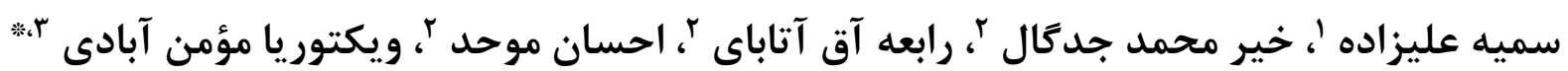
' دانشجوى دكترا، كروه آموزش بهداشت و ارتقاء سلامت، مركز تحقيقات بيمارىهاى مغز و اعصاب، دانشكاه علوم يزشكى كرمان، كرمان،

r r دانشجوى دكترا، كروه خدمات بهداشتى، دانشكده بهداشت، دانشكاه علوم يزشكى يزد، يزدة، ايران

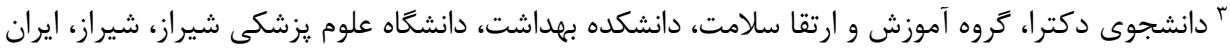

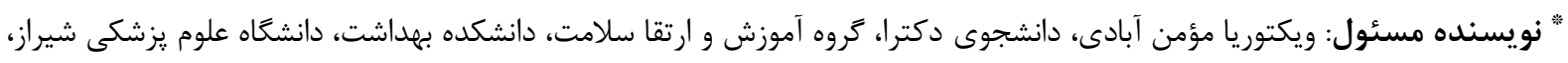

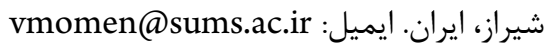

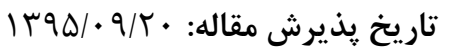

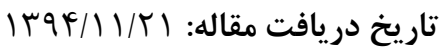

جكيده

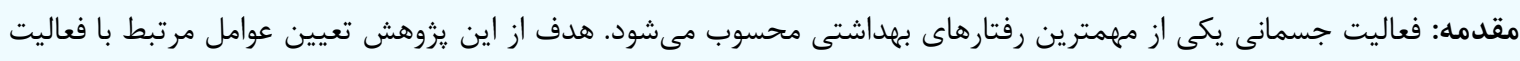

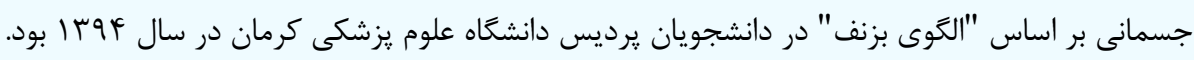

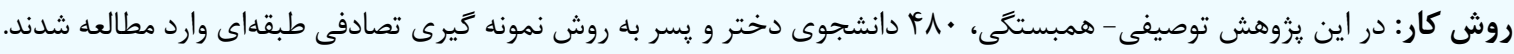

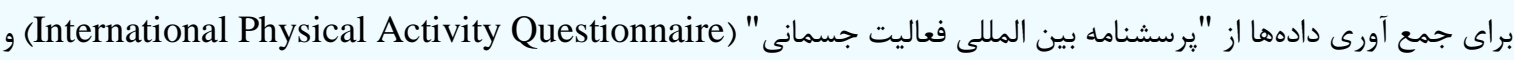

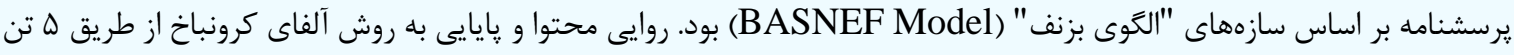

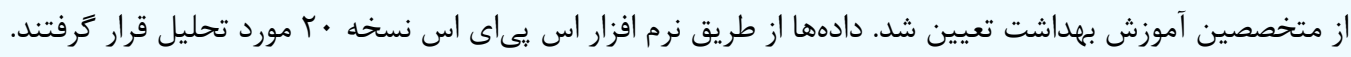

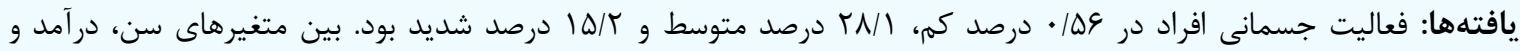

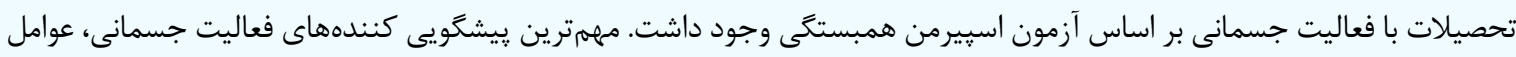
قادر ساز و قصد رفتارى بودند.

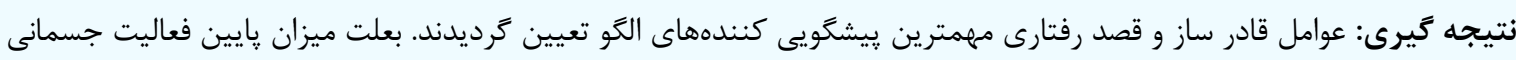

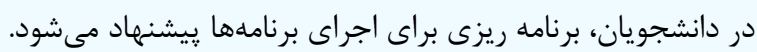

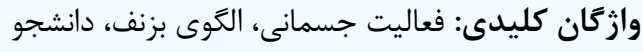
تمامى حقوق نشر براى انجمن علمى برستارى ايران محفوظ است.

شاخصهاى مردم سالم تا سال • · · معرفى شده است (V). فعاليت

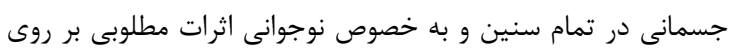

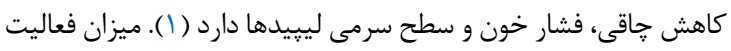

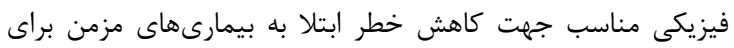

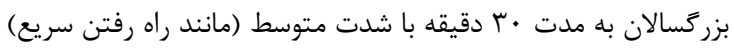

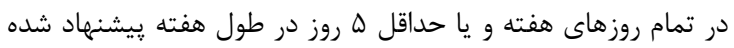

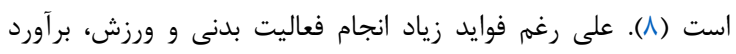

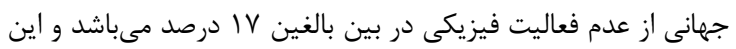

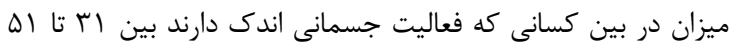

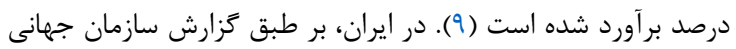

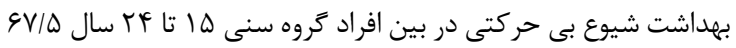

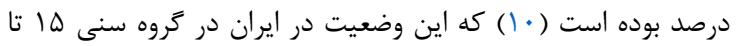

امروزه با توجه به بِيشرفت فناورى و ماشينى شدن زندگى در روند

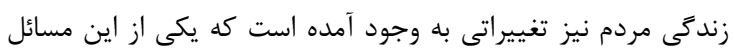

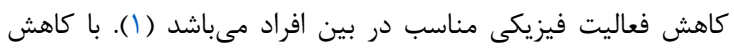

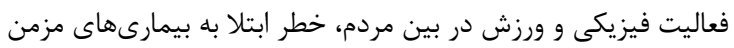

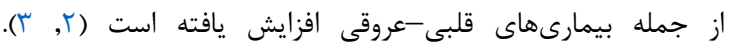
يزوهشهاى انجام شده حاكى از آن است كه خطر ابتلا به بيمارىهاى

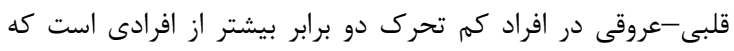

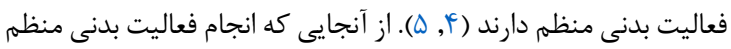

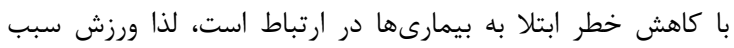

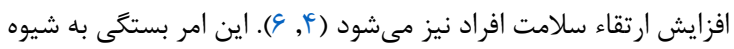

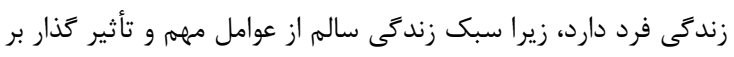

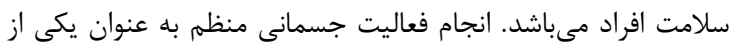


اطرافيان باعث افزايش فعاليت بدنى در دانشجويان بود. معينى و

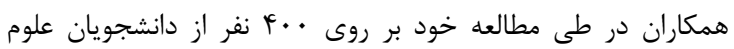

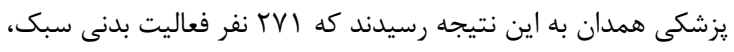

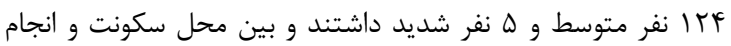
فعاليت بدنى نيز همبستخى معنادارى مبنى بر اينكه ساكنين خوابعاه

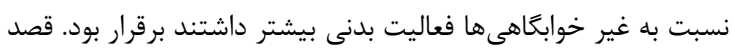

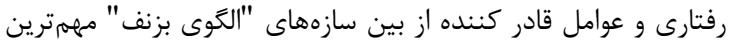

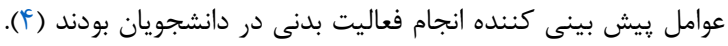

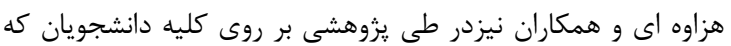

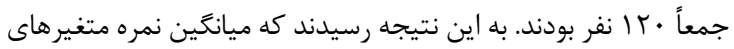

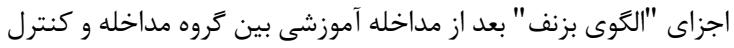

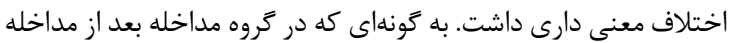

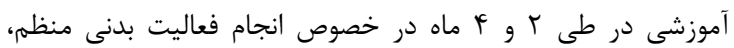

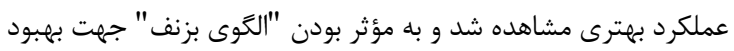

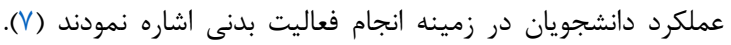

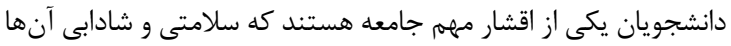

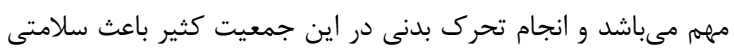

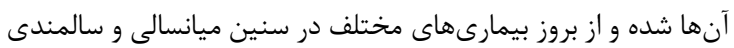

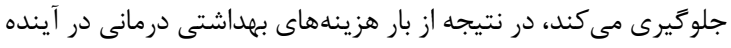

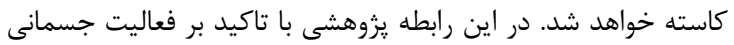

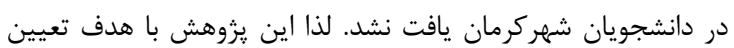

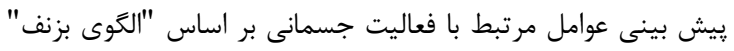

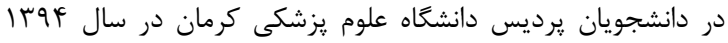

\section{روش كار}

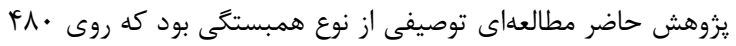

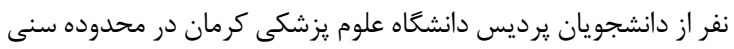

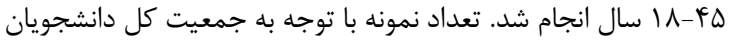

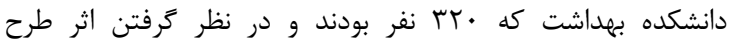

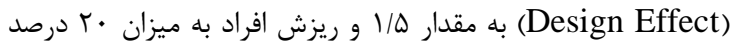

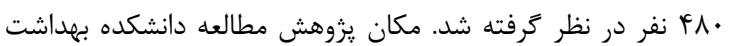

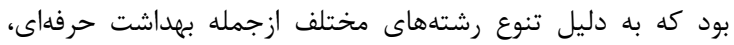

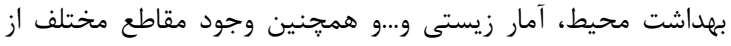

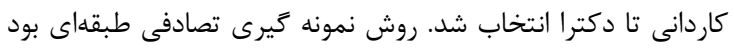

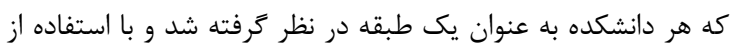

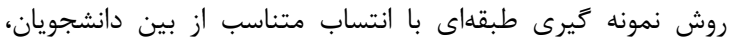

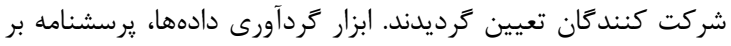

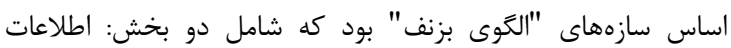

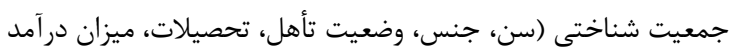

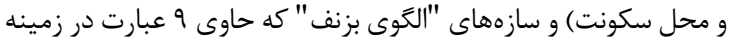
نحَرش (فكر مى كنم اگر فعاليت جسمانى داشته باشم مقبوليت من در

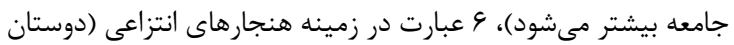

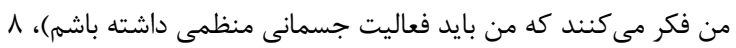

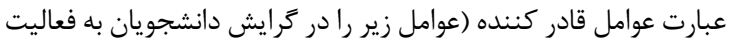

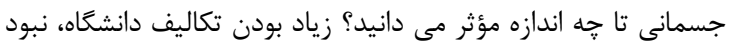

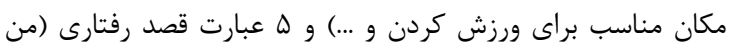

فع TF سال كاملاً مشهود است (F). از اين بين درصد كمى از جوانان در

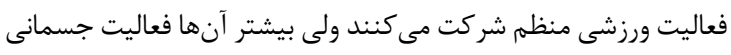

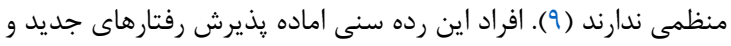

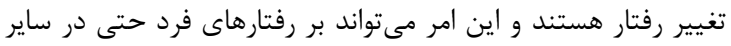

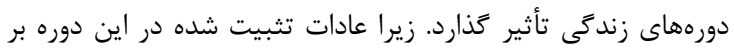

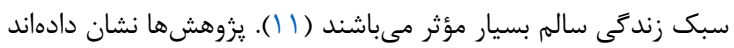

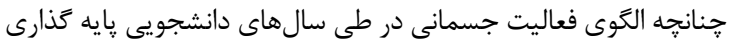

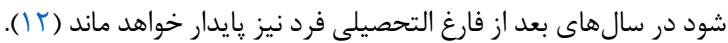

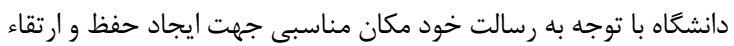

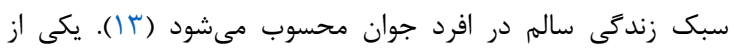

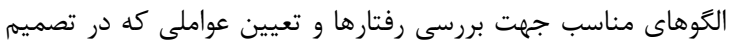

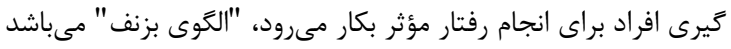

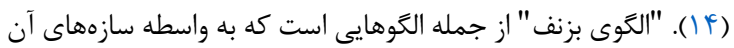

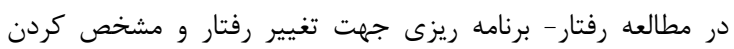

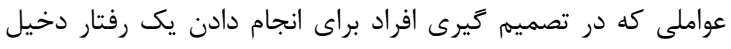

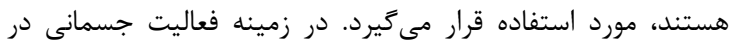

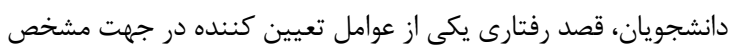

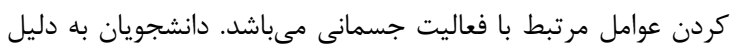

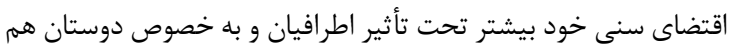

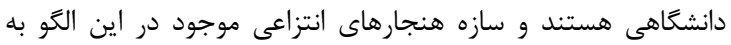

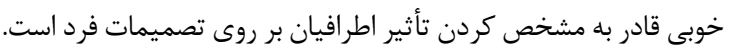

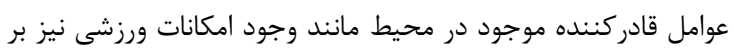

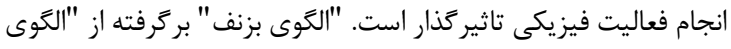

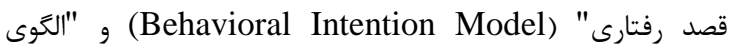
يرسيد" (PRECEDE Model) مى مباشد. نام اين الخو بركفته از حروف اول اجزاى آن است كه شامل رفتار (BASNEF)

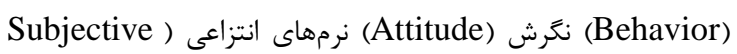

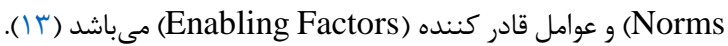
از اين الكو جهت برآورد نيازهاى آموزش بهداشت در كشور كشورهاى در حال

توسعه استفاده شده است (†) (تصوير ()).

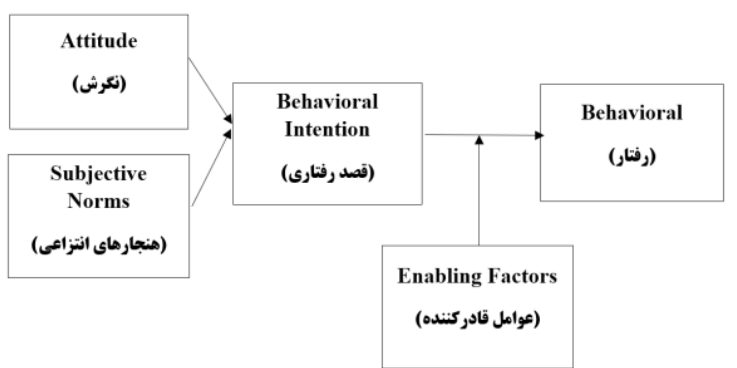

تصوير ا: حار ״وب مفهومى برنامه ريزى بر اساس "الكوى بزنف"

در طى مطالعهاى كه آقا ملايى و همكاران (9) بر روى •ده نفر از

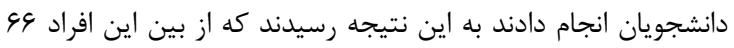

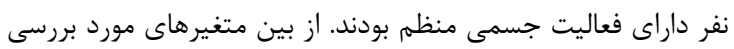

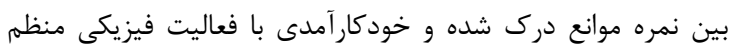

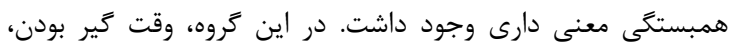

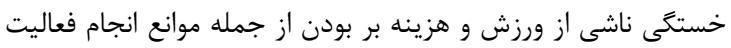

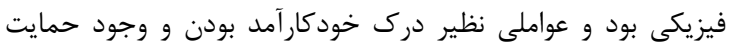




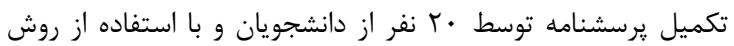

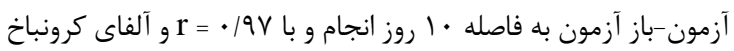

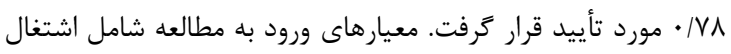

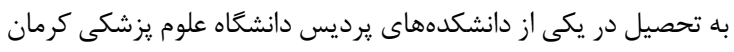

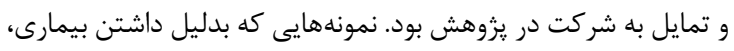

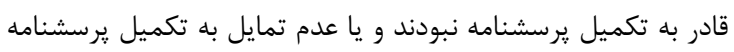

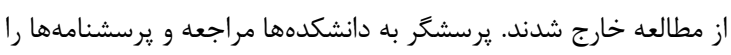

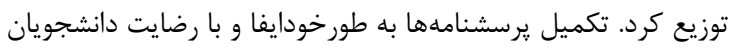

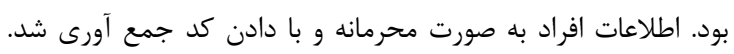

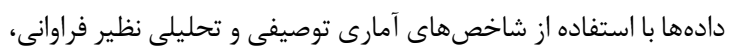

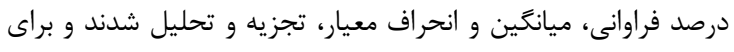

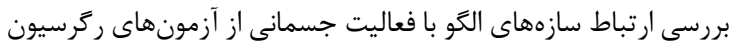

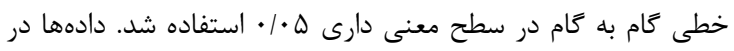
نرم افزار اس بيى اس اس نسخه • ب وارد و تحليل شدند.

\section{يافتهها}

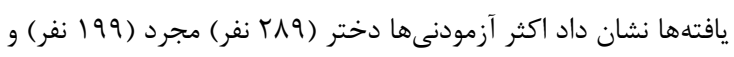

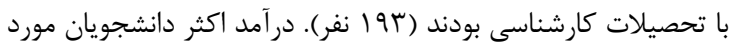

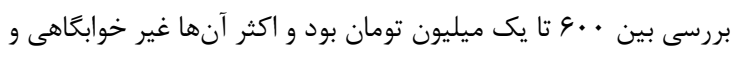

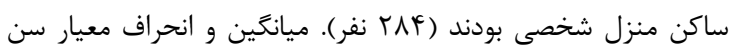

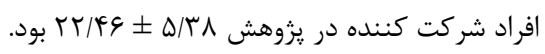

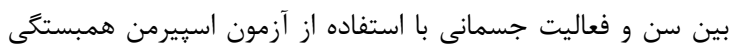

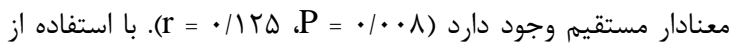

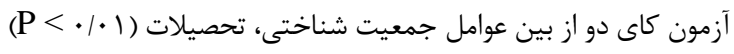

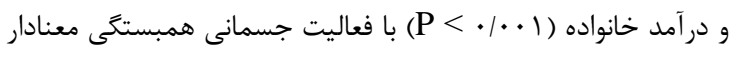

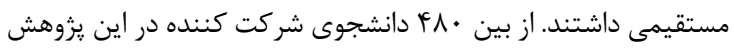

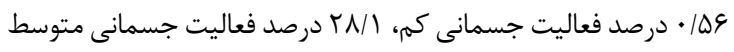

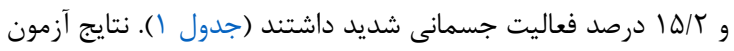

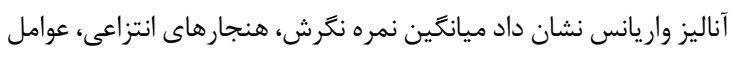

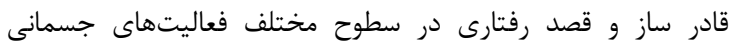

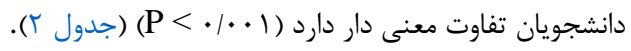

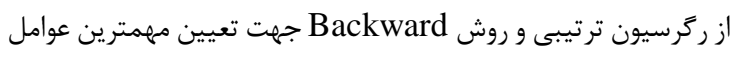

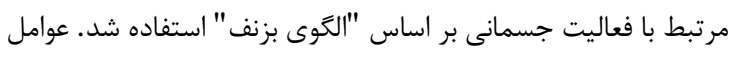

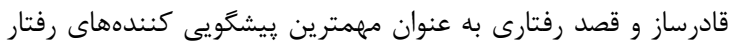

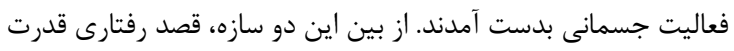

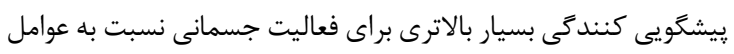
قادر ساز داشت (جدول س).
تصميم دارم در يك ماه آينده در يكى از باشعاههاى ورزشى ثبت نام

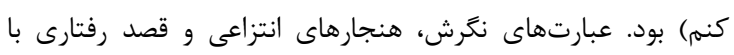

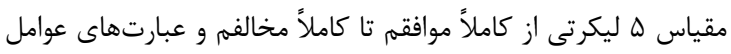

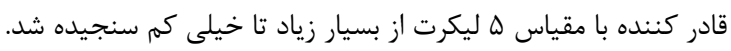

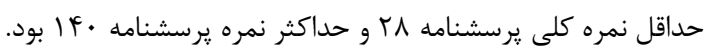

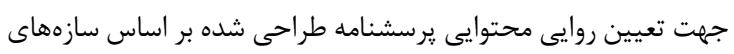

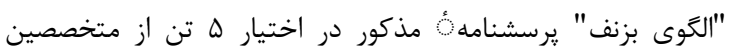

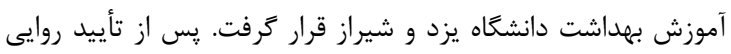

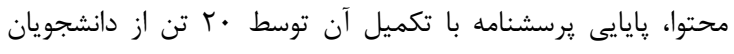

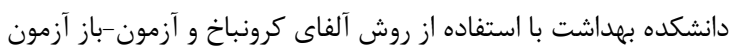

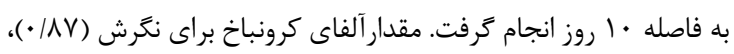

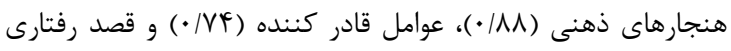

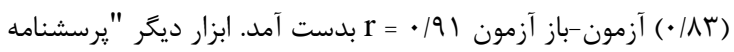

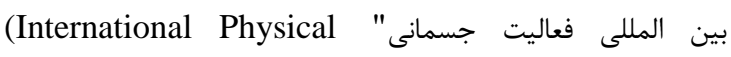
Activity Questionnaire) METs = فعاليـت جسـمانى كم، جسمانى متوسط و METs = به عنوان فعاليت جسمانى شديد در

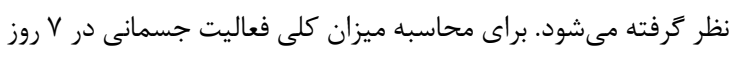

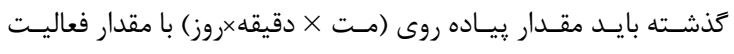

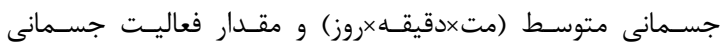

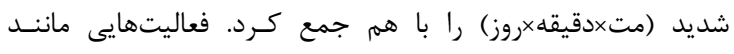

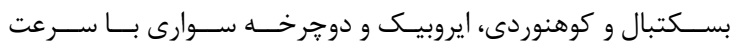

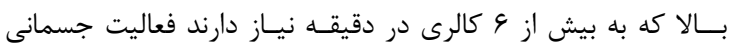

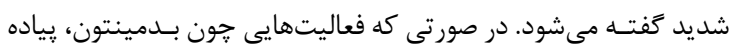

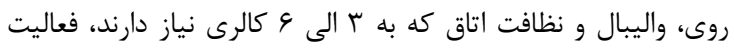

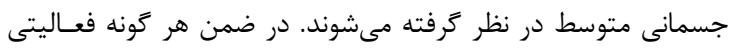

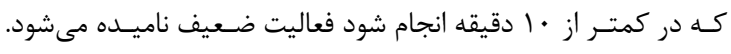

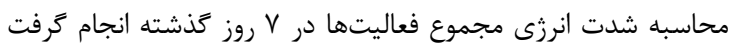

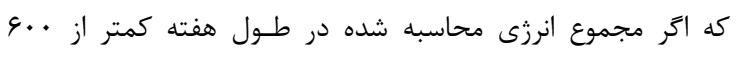

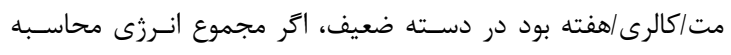

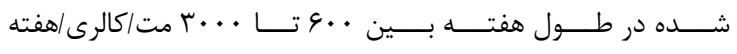

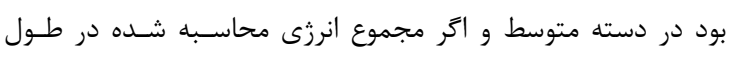

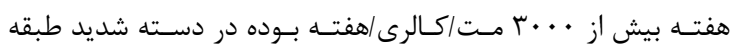

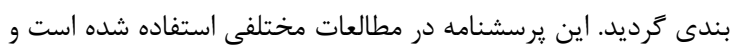

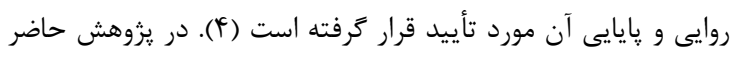

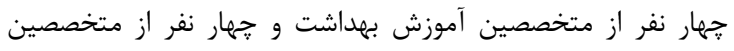

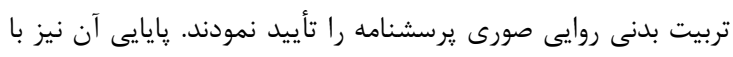

\begin{tabular}{|c|c|c|c|}
\hline & & \multicolumn{2}{|c|}{ جدول ا: ميانخين و انحراف معيار سازههاى "الكوى بزنف" } \\
\hline ماكزيمم & مينيمم & ميانگين 士 انحراف معيار & 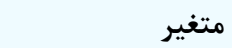 \\
\hline Fa & re & $F r / \Delta \pm T / T$ & 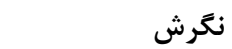 \\
\hline rq & 19 & $r r / \| \pm r / l r$ & 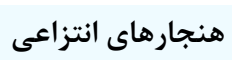 \\
\hline 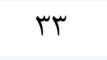 & r & $r / / V F \pm r / \Delta V$ & قصد رفتارى \\
\hline$r \cdot$ & $1 \cdot$ & $\mid r / g r \pm r / \Delta q$ & عوامل قادر ساز \\
\hline
\end{tabular}


جدول r: مقايسه ميانگين نمره سازههاى "الكَوى بزنف" در سطوح مختلف فعاليت جسمانى دانشجويان

\begin{tabular}{|c|c|c|}
\hline$P$ value & ميانگين 土 انحراف معيار & فعاليت جسمانى \\
\hline \multirow[t]{4}{*}{$<\cdot / \cdot \cdot 1$} & & نتخرش \\
\hline & $\kappa r / \cdot \Lambda \pm r / r$ & كم \\
\hline & $r r / / r \pm r / \cdot r$ & متوسط \\
\hline & $r r / \wedge q \pm r / r$ & 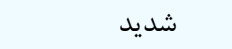 \\
\hline \multirow[t]{4}{*}{$<\cdot 1 \cdot \cdot 1$} & & هنجارهاى انتزاعى \\
\hline & $r T / \varepsilon \Delta \pm r / \cdot r$ & كم \\
\hline & $r r / \varphi \varepsilon \pm r / I V$ & متوسط \\
\hline & $r F / / \varepsilon \pm r / \cdot V$ & شديد \\
\hline \multirow[t]{4}{*}{$<\cdot / \cdot 1$} & & قصد رفتارى \\
\hline & $\mid r / r \cdot \pm 1 / \wedge \Delta$ & كم \\
\hline & $|\varepsilon / f| \pm r /||$ & متوسط \\
\hline & $r \cdot / r \cdot \pm r / r \Lambda$ & 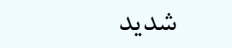 \\
\hline \multirow[t]{4}{*}{$<\cdot / \cdot \cdot 1$} & & عوامل قادر ساز \\
\hline & $r \cdot / 9 \varphi \pm r / \cdot \Lambda$ & كم \\
\hline & $r 1 / V q \pm r / r q$ & متوسط \\
\hline & $r F / \Delta \varepsilon \pm F / T F$ & 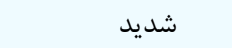 \\
\hline
\end{tabular}

\begin{tabular}{|c|c|c|c|c|c|}
\hline \multicolumn{2}{|c|}{ فاصله اطمينان ه9٪٪ } & $P$ value & SE & Estimate & متغير \\
\hline بيشترين & كمترين & & & & \\
\hline$\cdot / 1 r$ & $<\cdot / \cdot \cdot 1$ & $\cdot 1 \cdot \Delta$ & $\cdot / \pi \Delta$ & $\cdot 199$ & عوامل قادر ساز \\
\hline $1 / 1$ & $\cdot|\Lambda|$ & $<\cdot / \cdot 1$ & $\cdot / \cdot V$ & .199 & قصد رفتارى \\
\hline
\end{tabular}

طرفى ديگر، رستمى معز و همكاران در طى يزوهش خود رابطه معنى

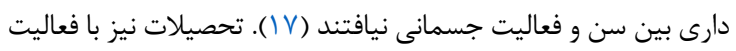

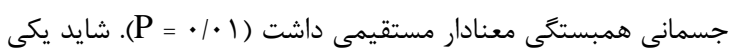

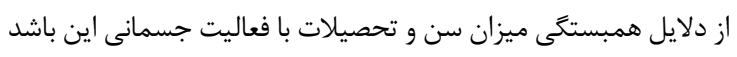

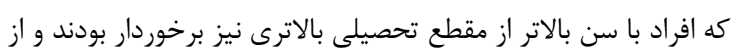

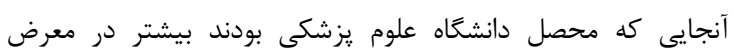

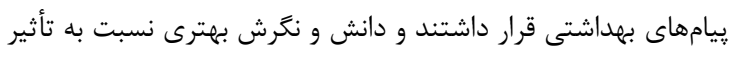

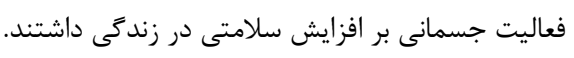

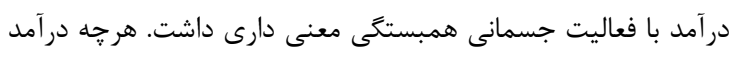

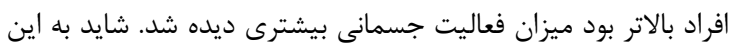

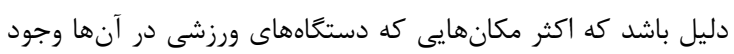

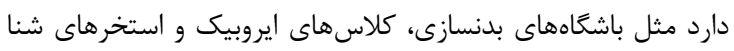

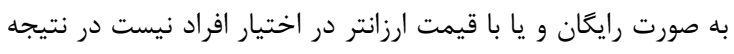

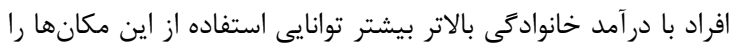

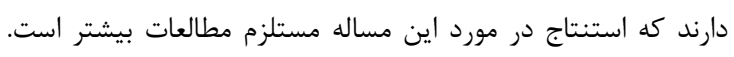

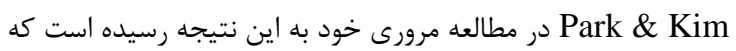
در بعضى از مطالعات بين وضعيت اجتماعى اقتصادى و فعاليت جسمانى

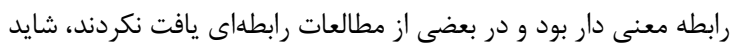

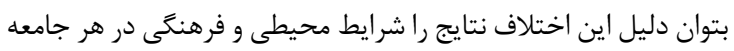

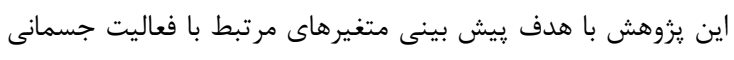

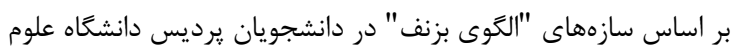

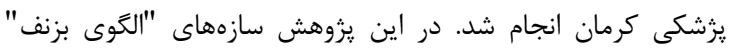

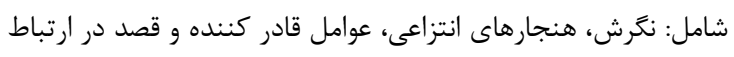

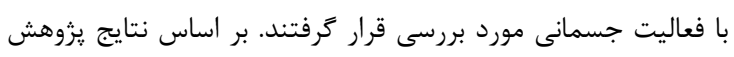

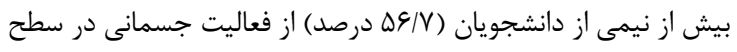

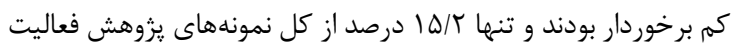

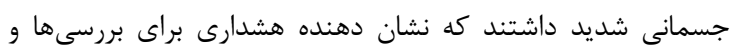

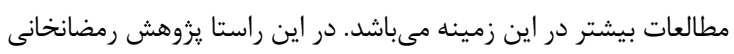

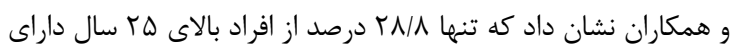

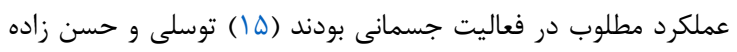
در طى يزوهش خود وضعيت عملكرد فعاليت جسمانى افراد مورد مورد

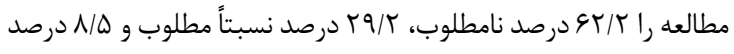

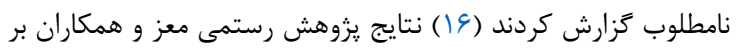

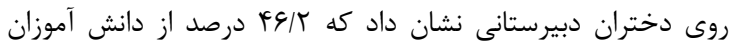

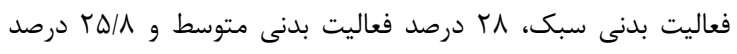

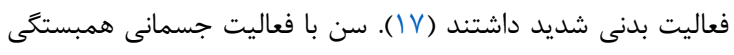
معنى دار مستقيمى داشت، به اين معنى كه هرجه

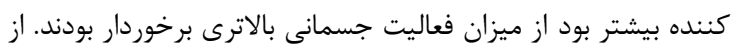


جسمانى همبستخى معنى دار مستقيمى داشت. به اين معنى كه هرجه

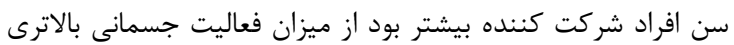

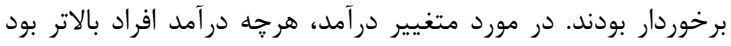

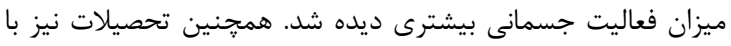

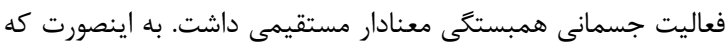

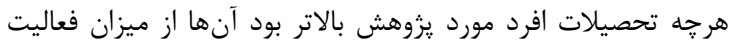

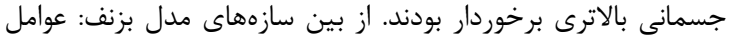

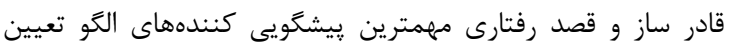

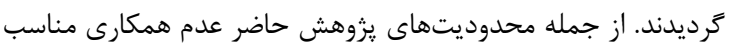

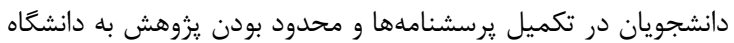

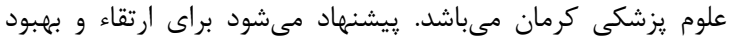

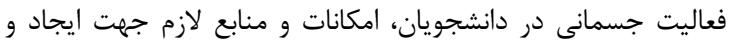

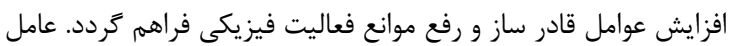

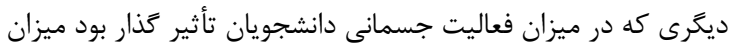

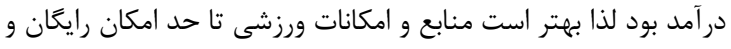
يا با هزينه پايين در اختيار دانشجويان قرار داده شود.

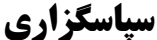

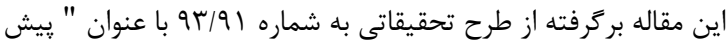

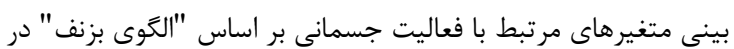

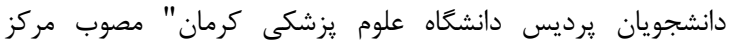

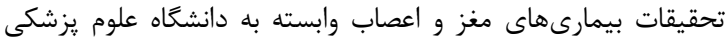

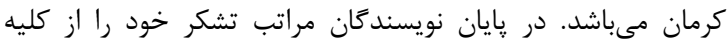

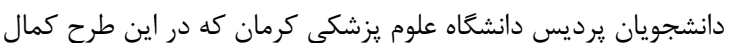

$$
\text { همكارى را داشتند ابراز مى دارند. }
$$

\section{References}

1. Solhi M, Zinatmotlagh F, Karimzade Shirazi K, Taghdisi MH, Jalilian F. [Designing and implementing educational program to promote physical activity among students: An application of the theory of planned behavior]. Q Horiz Med Sci. 2012;18(1):45-53.

2. Hazavehei SMM, Asadi Z, Hassanzadeh A, Shekarchizadeh P. [Comparing the effect of two methods of presenting physical education $\Pi$ course on the attitudes and practices of female Students towards regular physical activity in Isfahan University of Medical Sciences]. Iranian J Med Educ. 2008;8(1):121-31.

3. Burton NW, Turrell G. Occupation, hours worked, and leisure-time physical activity. Prev Med. 2000;31(6):673-81. DOI: 10.1006/pmed.2000.0763 PMID: 11133334

4. Moeini B, Jalilian F, Jalilian M, Barati M. [Predicting factors associated with regular physical activity among college students applying basnef model]. Sci J Hamadan Univ Med Sci. 2011;18(3):70-6.

5. Elosua R. [Physical activity. An efficient and underused way of preventing cardiovascular disease from childhood to old age]. Rev Esp Cardiol. 2005;58(8):887-90. PMID: 16053820

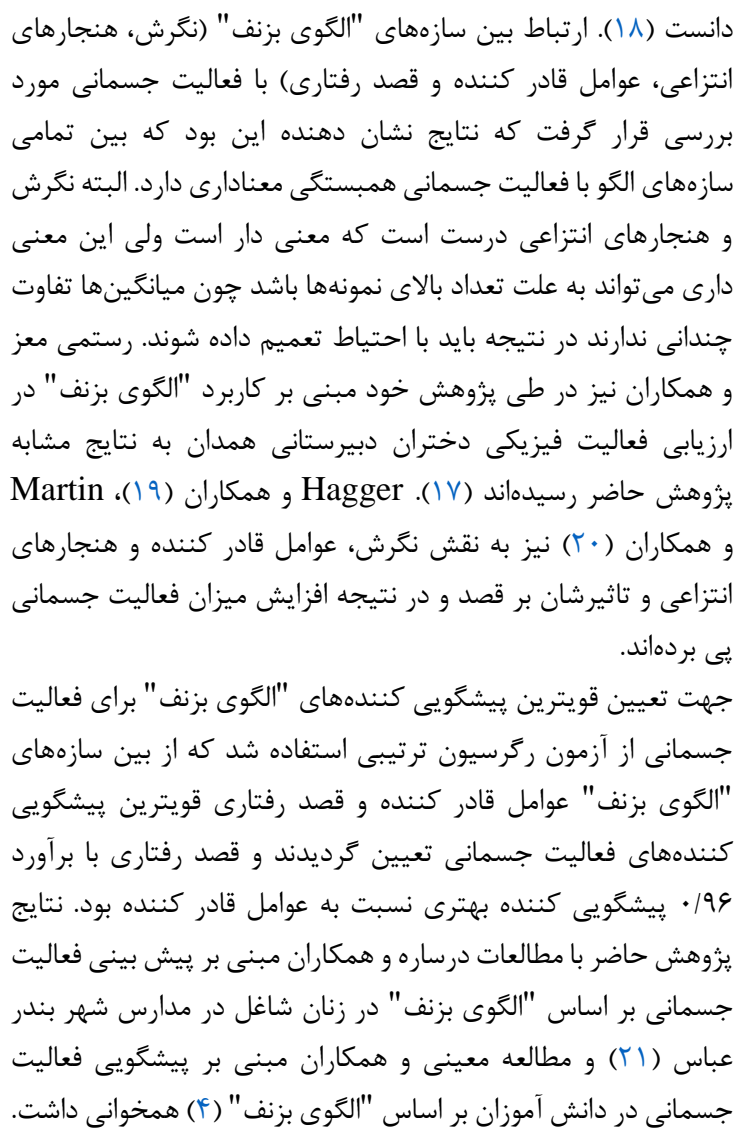

\section{نتيجه گيرى}

در اين مطالعه بيشتر دانشجويان از فعاليت جسمانى در سطح كم برخوردار بودند. از بين متغيرهاى جمعيت شناختى سن بن با فعاليت

6. Tavafian S. [Exercise self-efficacy, exercise perceived benefits and barriers among students in Hormozgan University of Medical Sciences]. Iranian J Epidemiol. 2009;4(3):9-15.

7. Hazavehei S, Asadi Z, Hasanzade A, Shekarchizadeh P. [A Study on the Effect of Physical Education (П) Curriculum Based on BASNEF Model on Female Students' Regular Physical Activity in Isfahan University of Medical Sciences]. ZUMS J. 2009;17(69):70-83.

8. Kelishadi R, Kahbazi M, Rabiei K, Heidari S, Doreh F, Baghaie A. [Physical activity level among children of markazi and Isfahan provinces]. Arak Med Uuniv J. 2004;7(1):26-33.

9. Zeidi I, Ziaeiha M, Variani AS, Khalaj M, Zeidi B, Tonekaboni H. [Predicting the stages of change in physical activity behavior of QUMS students with Pender's model]. J Qazvin Univ Med Sci. 2010;14:5866.

10. Wallberg-Henriksson H, Rincon J, Zierath JR. Exercise in the management of non-insulin-dependent diabetes mellitus. Sports Med. 1998;25(1):25-35. PMID: 9458525

11. Welk GJ, Corbin CB, Dale D. Measurement issues in the assessment of physical activity in children. Res Q 
Exerc Sport. 2000;71 Suppl 2:59-73. DOI: 10.1080/02701367.2000.11082788 PMID: 25680015

12. Sallis JF, Prochaska JJ, Taylor WC. A review of correlates of physical activity of children and adolescents. Med Sci Sports Exerc. 2000;32(5):96375. PMID: 10795788

13. Safari M, Shojaei-zade D, Ghofrani F, Hedarnya A, Pakpor A. [Health education and promotion]. Knowledge Edition ed. Tehran: Sobhan; 2012.

14. Sparling PB. College physical education: an unrecognized agent of change in combating inactivityrelated diseases. Perspect Biol Med. 2003;46(4):57987. PMID: 14593225

15. Ramezankhani A, Matlabi Ghaen M, Tavasoli A, Babaie A. [The survey of knowledge, attitude and practice of students living in the dormitories of Shahid Beheshti University of Medical Sciences of Physical Activity]. J Educ Health Prom. 2013;1(1):13-20.

16. Tavasoli E, Hasanzade A. [Study of knowledge, attitude and practice of Isfahan the second grade middle school girl students toward prevention of osteoporosis based on of Health Belief Model]. Zahedan J Res Med Sci. 2012;13(9):59-.
17. Rostami Moez M, Hazavehei S, Moeini B, Roshanaei G, Taheri M. [Applying BASNEF Model for Predicting Regular Physical Activity of Female High School Students in Hamadan: A cross- sectional theory based study]. ZUMS J. 2014;22(92):96-107.

18. Park H, Kim N. Predicting factors of physical activity in adolescents: a systematic review. Asian Nurs Res (Korean Soc Nurs Sci). 2008;2(2):113-28. DOI: 10.1016/S1976-1317(08)60035-3 PMID: 25031244

19. Hagger MS, Chatzisarantis NL, Biddle SJ. The influence of autonomous and controlling motives on physical activity intentions within the Theory of Planned Behaviour. Br J Health Psychol. 2002;7(Part 3):283-97. DOI: 10.1348/135910702760213689 PMID: 12614501

20. Martin JJ, Oliver K, McCaughtry N. The theory of planned behavior: predicting physical activity in Mexican American children. J Sport Exerc Psychol. 2007;29(2):225-38. PMID: 17568068

21. Darsareh F, Aghamolaei T, Ghanbarnejad A. [Prediction of Physical Activity based on BASNEF Model Constructs among female teachers in Schools of Bandar Abbas]. J Prev Med. 2015;2(1):1-9. 


\title{
Factors Related to Physical Activity based on "BASENF Model” in Kerman University of Medical Sciences Students
}

\author{
Somayyeh Alizadeh ${ }^{1}$, Kheir Mohammad Jadgal ${ }^{2}$, Rabe'e Age Atabay ${ }^{2}$, Ehsan \\ Movahed $^{2}$, Victoria Momenabadi ${ }^{3, *}$
}

\author{
${ }^{1} \mathrm{PhD}$ Student, Department of Health Education and Health Promotion, Neurology Research \\ Center, Kerman University of Medical Sciences, Kerman, Iran \\ ${ }^{2} \mathrm{PhD}$ Student, Department of Health Education and Health Promotion, School of Public Health, \\ University of Medical Sciences, Yazd, Iran \\ ${ }^{3} \mathrm{PhD}$ Student, Department of Health Education and Health Promotion, School of Health, Shiraz \\ University of Medical Sciences, Shiraz, Iran \\ * Corresponding author: Victoria Momenabadi, PhD Student, Department of Health Education and Health \\ Promotion, School of Health, Shiraz University of Medical Sciences, Shiraz, Iran. E-mail: vmomen@sums.ac.ir \\ Received: 10 Feb 2016 \\ Accepted: 10 Dec 2016
}

\begin{abstract}
Introduction: Physical activity is one of the most important health behaviors. The aim of this study was to determine the factors related to physical activity based on the "BASENF Model" in Kerman University of Medical Sciences in 2016.

Methods: In this descriptive-correlational study, 480 male and female students were selected through stratified sampling. To collect data, the "International Physical Activity Questionnaire" and a questionnaire based on the "BASNEF Model" were used. Content validity and reliability by Cronbach's alpha was determined by five experts. Data was analyzed by SPSS 20 .

Results: In this study, physical activity levels at $0.56 \%, 28.1 \%$ and $15.2 \%$ were considered as low, moderate and high, respectively. There was a correlation in age, income and education, with physical activity. The most important predictors of physical activity were enabling factors and behavioral intention.

Conclusions: Enabling factors and behavioral intention were determined as the two most important predictors of the model. Due to low physical activity in students, planning physical activity sessions are suggested.

Keywords: Physical activity, BASNEF Model, Student
\end{abstract}

